\title{
Entre margens: Guimarães Rosa na sala de aula
}

\author{
Between the margins: Guimarães Rosa in the classroom
}

\begin{abstract}
Júlio de Souza Vale Neto
Doutor em Teoria e História Literária pela Universidade Estadual de Campinas. Professor do Curso de Letras da Universidade Federal de São Paulo. São Paulo - SP - Brasil juliovalleunifesp@gmail.com

Lara Silva Perussi Bertão Mestranda em letras pela Universidade Federal de São Paulo. São Paulo - SP - Brasil lara.perussi@hotmail.com

Nayra Mikie Dias Kikuchi Mestranda em letras pela Universidade Federal de São Paulo. São Paulo - SP - Brasil nayra03@hotmail.com
\end{abstract}

Resumo: Este artigo propõe uma abordagem didática para "A Terceira Margem do Rio", um dos mais famosos contos de Guimarães Rosa. Neste contexto, sugerem-se alguns aspectos para a sua abordagem no Ensino Médio, bem como algumas possíveis atividades de avaliação. Baseado em diferentes fontes teóricas - que combinam documentos oficiais como os PCN (Parâmetros Curriculares Nacionais) e as OCEM (Orientações Curriculares para o Ensino Médio), alguns estudiosos do ensino de literatura como Vincent Jouve e diferentes trabalhos críticos sobre "A Terceira Margem do Rio" - , o texto pretende destacar a importância da literatura na escola, na qual o professor desempenha um papel específico e mesmo crucial.

Palavras-chave: Literatura. Ensino. Conto. Guimarães Rosa.

\begin{abstract}
This paper shows a didactical approach of "A Terceira Margem do Rio", one of the most famous short stories written by Guimarães Rosa. In this context, we suggest some aspects to approach this text at the High School level, including possible evaluation activities. Based on different theoretical sources - which combines official documents as PCN (National Curriculum Parameters) and OCEM (Curriculum Orientations of High Schoo), some authors who think about literary teaching as Vincent Jouve and different critical works about "A Terceira Margem do Rio" -, we intend to highlight the importance of literature in the school, where teacher develops a specific role, even crucial.
\end{abstract}

Keywords: Literature. Teaching. Short Story. Guimarães Rosa. 


\section{Considerações Iniciais}

Considerando a leitura enquanto uma atividade complexa e multifacetada, que pode ser entendida como um processo de cinco dimensões - neurofisiológica, cognitiva, afetiva, argumentativa e simbólica (JOUVE, 2002) ${ }^{1}$-, este artigo tem por objetivo, ocupando-se da relação entre leitura e educação, apresentar uma proposta de aula de Literatura Brasileira concebida para o último ano do Ensino Médio, a partir da qual se vislumbram alternativas metodológicas para a valorização da leitura literária no espaço escolar.

Salienta-se que o ensino de Literatura nas escolas é regulado por diversos documentos oficiais, como os Parâmetros Curriculares Nacionais $(\mathrm{PCN})^{2}$ e as Orientações Curriculares para o Ensino Médio (OCEM). Em se tratando das Orientações, concebe-se o texto literário de modo mais complexo do que mais um modo discursivo dentre vários, sendo assim diferenciado não só pela elaboração linguística que prevê, mas também pela transgressão decorrente do exercício de liberdade proporcionado aos leitores, donde se conclui que a função da arte e, por isso, da literatura, dentro e fora das instituições de ensino constitui-se

[...] como meio de educação da sensibilidade; como meio de atingir um conhecimento tão importante quanto o científico - embora se faça por outros caminhos; como meio de pôr em questão (fazendo-se crítica, pois) o que parece ser ocorrência/decorrência natural; como meio de transcender o simplesmente dado, mediante o gozo da liberdade que só a fruição estética permite; como meio de acesso a um conhecimento que objetivamente não se pode mensurar [...]. (BRASIL, 2006, p. 52-3).

Dessa forma, elegeu-se o conto "A terceira margem do rio", publicado originalmente em 1962, no livro Primeiras Estórias, por acreditar-se que tal escrito roseano compreende a pluralidade significativa inerente às grandes obras literárias, uma vez que, suscitando desde o seu título a ambientação do insólito, o texto propicia “[...] um agenciamento metafórico, plural, criativo, provocativo do mundo [...]" (DALVI, 2013, p. 84). Submetido a uma mediação pertinente, crê-se que o conto atraia o interesse do leitor, seja porque problematiza questões contemporâneas próprias do meio social a que pertence, seja porque, distanciandose e aproximando-se de tais questões, dentro de suas camadas de "insolidez", constitui-se como “[...] 'álgebra mágica’ que por mais indeterminada é mais exata.” (BRAGANÇA, 2000, p. 662). Pretende-se, então, que os alunos adentrem no universo místico construído pelo texto, valorizando-se, a partir de suas leituras, os "lugares de incerteza" (JOUVE, 2012, 
p.150) abundantes no conto, de forma a nele encontrar, senão as respostas, as perguntas não satisfeitas pelo mundo real.

\section{Desenvolvimento da aula}

Entendendo, pois, a importância da Literatura no ensino e o papel que desempenha na formação crítica dos alunos, pretende-se, neste momento, apresentar estratégias didáticas de abordagem do conto roseano "A terceira margem do rio" em sala de aula.

Em princípio, é desejável que uma leitura prévia e individual do conto seja realizada por todos os alunos da turma. Este contato inicial com o texto é necessário ao sujeito leitor na medida em que, a partir dele, se estabelecerão algumas das "dimensões" mencionadas por Jouve, notadamente a afetiva e a cognitiva. A ocasião, portanto, é relevante para a elaboração das primeiras hipóteses interpretativas, sendo recomendável, para a otimização dessa etapa, encorajar a escrita de notas à margem do texto, de inspirações diversas.

Na primeira aula dedicada à análise, propor-se-ia uma leitura em voz alta do conto, devido à sua complexidade linguística, bem como ao fato de que "ler para o outro nunca é apenas oralizar um texto. Ledor e ouvinte dividem mais que a reprodução sonora do escrito, eles compartilham um interesse pelo mesmo texto, uma interpretação construída e conduzida pela voz, além de outras influências recíprocas." (COSSON, 2014, p. 104). No mesmo sentido, Daniel Pennac elenca os efeitos produzidos, no ouvinte, a partir da escuta de um texto lido competentemente em vOz alta:

Se ele lê verdadeiramente, põe nisso todo o seu saber, dominando seu prazer, se sua leitura é um ato de simpatia pelo auditório como pelo texto e seu autor, se consegue fazer entender a necessidade de escrever, acordando nossas mais obscuras necessidades de compreender, então os livros se abrem para ele e a multidão daqueles que se acreditavam excluídos da leitura vai se precipitar atrás dele. (PENNAC, 1993, p. 166).

A leitura em voz alta, portanto, abarca desde as camadas mais básicas de leitura, incluindo as de compreensão textual, até propriamente as camadas interpretativas, constituindo-se numa oportunidade para que, desde logo, identifiquem-se pontos a serem explorados ao longo da mediação. Em seguida, tendo dividido a sala em grupos, com a finalidade de instigar um trabalho de construção coletiva de sentido, eles exporiam as suas hipóteses iniciais de leitura, que compreendessem tanto uma possível explicação para o título 
“A terceira margem do rio" quanto a elaboração de um glossário, capaz de contemplar as questões espontaneamente surgidas a partir da discussão preliminar. Para esse fim, seria de utilidade, além da mediação do professor, a pesquisa em dicionários ou suportes eletrônicos. A escolha das novas tecnologias da informação e comunicação (TICs) como instrumento didático fundamenta-se na ideia de que elas possam contribuir no processo de ensinoaprendizagem, ainda que este seja um assunto controverso nas discussões mais recentes sobre o posicionamento da escola frente à era digital. Contudo, como lembra Rojo, "em vez de proibir o celular em sala de aula, posso usá-lo para comunicação, a navegação, a pesquisa, a filmagem e a fotografia" (2012, p. 27).

Posteriormente, de acordo com as exposições dos alunos, enquanto mediador de leitura, caberia ao professor apontar possíveis equívocos e extrapolações interpretativas, uma vez que o texto literário está sujeito a diferentes interpretações, mas não admite incoerências:

Se é conveniente encorajar a leitura subjetiva, é também conveniente ensinar os alunos a evitarem uma subjetividade desenfreada, fonte de delírio interpretativo. O problema da liberdade do leitor e dos limites da interpretação deve ser abordado em classe, mesmo que isso pareça ambicioso. [...] Eles são capazes de compreender que existem muitas maneiras de ler e que uma leitura socializada impõe regras. (ROUXEL, 2013, p. 22).

Feitas as reparações, na tentativa de imergi-los no universo ficcional do conto, o professor dirigiria perguntas aos alunos, formulando-as de modo preferencialmente indireto, no âmbito das questões surgidas a propósito da conversa prévia. O processo supõe, portanto, um movimento inicial, mais aberto, a partir do qual ele se torna gradativamente mais dirigido. Dentre as questões de interesse, a serem naturalmente filtradas ou adaptadas de acordo com as devolutivas iniciais da turma, teríamos as seguintes: "Qual o cenário da narrativa?”; "O que vocês pensam acerca da linguagem pela qual as personagens se expressam?”; "Vocês já tinham ouvido falar do autor? Se sim, o que ouviram?”; “Quais são as personagens do conto e quais suas impressões acerca delas?”; "Qual o perfil do narrador?” e "Qual, na opinião de vocês, é o principal conflito do conto?”. Nesse processo de imersão, os estudantes seriam incentivados a estabelecer relações entre as informações ficcionais e situações reais, as quais, vivenciadas ou não, fariam parte do conhecimento que têm do mundo. Isto é, a partir das inquietações dos alunos, a discussão seria aprofundada por um viés teórico. 
Sobre o cenário, conviria apresentá-lo como uma região não especificada, mas identificável como sendo o mundo da infância e mocidade do autor, o sertão de Minas (RÓNAI, 1981, p. XXIV-V). Dessa forma, o professor poderia contextualizar brevemente o Movimento Regionalista, abordando, junto a essa questão, a linguagem empregada no conto, a qual não se restringe à simples reprodução de um falar sertanejo, mas se apropria dele visando à criação do que Rónai denomina "insólitas locuções individuais” (1981, p. XXXIII), uma vez que, para além de expressões pouco utilizadas comumente como "entestou", “achaques", ou neologismos como "demoramento" e "subimento", encontramos a presença constante de expressões que, repetidas em seu caráter insólito, reforçam a dimensão fantástica dos próprios acontecimentos do texto. É bom lembrar, contudo, que muito desse aspecto criativo já terá sido abordado, muito provavelmente, pelos próprios alunos, especialmente na etapa em que, se valendo de instrumentos de pesquisa como dicionários ou a web, terão visto frustradas, em parte, algumas de suas consultas, na uma vez que várias expressões, justamente por neologísticas ou inusuais, não se encontram dicionarizadas. $O$ aparente fracasso (ao menos parcial) dessas pesquisas revela-se funcional, entretanto, em dois níveis: primeiro, para reforçar ou, se for o caso, introduzir o próprio conceito de "neologismo" e, segundo, para ilustrar, precisamente, um dos níveis transgressivos de que o texto literário, como lembra as OCEM, legitimamente se reveste enquanto forma de arte. Nesse âmbito, é coerente recorrer ao próprio texto literário em questão, evidenciando pelo menos um trecho no qual se evidencia essa insolidez linguística:

Sou homem de tristes palavras. De que era que eu tinha tanta, tanta culpa? Se o meu pai, sempre fazendo ausência: e o rio-rio-rio, o rio-pondo perpétuo. Eu sofria já o começo - esta vida era só o demoramento. Eu mesmo tinha achaques, ânsias, cá de baixo, cansaços, perrenguice de reumatismo. (ROSA, 1981, p. 31).

Em relação às personagens, valeira a pena destacar traços que lembram a antiga estrutura patriarcal no Brasil, ainda presentes no interior do país, como lembra Ana Paula Pacheco:

O respeito do mais novo pelo mais velho, o direcionamento da vida do filho espelhada na do pai, num sistema de produção rural onde pouco varia o papel e o lugar reservado a cada indivíduo no grupo, lembra uma ordem social fundada em laços patriarcais, com costumes arraigados. (PACHECO, 2006, p. 147). 
A ausência do pai na ficção e, por conseguinte, a maior responsabilidade da mãe na criação dos filhos, provavelmente, seria um aspecto, com o qual, boa parte dos alunos se identificaria ou reconheceria como recorrente na sociedade. Pela mitificação da situação corriqueira do abandono paterno, esses leitores estariam diante da "[...] descoberta de uma gama de sentimentos que a elaboração poética tramou, desvendou e criou em torno de um fato [...]" (OSAKABE, 2008, p. 51). Dados externos, como os indicadores sociais sobre a mulher, fornecidos pelo IBGE, poderiam ser somados à discussão, permitindo uma abordagem interdisciplinar no estudo, como previsto nos documentos oficiais. ${ }^{3} \mathrm{O}$ movimento se reveste de importância na medida em que o ensino de literatura, ao menos potencialmente, vincula-se à maturação afetiva dos alunos e, portanto, ao desenvolvimento de sua autonomia enquanto sujeitos. Em outras palavras, "como os problemas do homem e do mundo não são simples, precisam de soluções complexas, interdisciplinares." (NEVES, 2015, p.482)

Em seguida, é conveniente que a sala seja conduzida a refletir acerca das razões e dos efeitos discursivos da narração em primeira pessoa: a priori é possível perceber, como discorre Del Farra (1978, p. 51), que o enredo ganha sentido a partir da voz do narrador, restrita à percepção que ele tem dos acontecimentos e que oculta e desvela o que lhe convém. Concomitantemente, pode-se notar que o fato do narrador se posicionar como um "eu" permite ao leitor estabelecer um contato mais direto com o texto, bem como ser evidenciada a aproximação simbólica, quase fatídica, entre o filho (narrador) e o pai (aquele sobre quem se narra):

\footnotetext{
'A terceira margem do rio' é uma narrativa em primeira pessoa; essa escolha técnica convencional concentra uma peculiaridade que não passa despercebida ao leitor: a voz que conta a história do pai conta também a sua, à sombra deste, um trajeto em que a demora e a inércia tomaram o lugar das decisões. Entre testemunha e protagonista, o filho não tem nem um recuo do primeiro, dado pela clara distinção entre eu e outro, nem a relevância do segundo, e fica, também ele, no meio do caminho." (PACHECO, 2006, p. 158).
}

Retomando um aspecto já salientado no início da aula proposta, destaca-se a oportunidade do docente, a partir das respostas que os alunos deram em relação ao possível sentido do título, abordar o caráter insólito do conto. Tomando como pressuposto a inexistência de uma terceira margem do rio (nas palavras de Limia, "a margem que não se fixa, maleável, mutante, que não cria normas e, portanto, não aprisiona.” ( 2000, p. 327)), 
seria possível indagar, então, acerca da racionalidade e/ou irracionalidade do narrado. Desse modo, no tocante ao principal conflito do conto, seria de interesse indagar se a incoerência do título estaria, possivelmente, relacionada ao suposto transtorno mental do pai do narrador, bem como se o filho, cogitando tomar a mesma atitude do pai, substituindo-o na terceira margem, teria também enlouquecido. O conceito de loucura, assim, seria posto no centro da discussão, permitindo questionar, por exemplo, se todas as atitudes do homem, dispondo de pleno estado mental, seriam motivadas pela razão, e mesmo na difícil precisão do limiar entre a sanidade e a loucura. Para melhor discorrer acerca da relatividade da loucura, evocada direta e indiretamente no texto, seria interessante mencionar obras como Elogio da loucura (1511) de Erasmo de Rotterdam, a História da Loucura na Idade Clássica (1972) de Michel Foucault e até mesmo a peça shakespeariana Hamlet (1602), obras que, respectivamente, satirizam, teorizam e tematizam a loucura (ainda que fingida), demonstrando o quão frutífero tem sido esse tema nos campos filosófico, religioso e literário. Em relação à literatura brasileira, especificamente, nunca seria demais remeter ao conto O Alienista, de Machado de Assis, ficando a cargo do professor graduar a quantidade de informações oferecidas a seu respeito, posto que a leitura da obra, em momento posterior, pode ser instigada ou orientada a partir dessa intervenção a propósito de Rosa.

A propósito do desfecho surpreendente do conto, seria pertinente questionar os alunos acerca de aspectos que reforçam o teor insólito ou mesmo sobrenatural do texto. Interessa, por exemplo, inquirir do que, possivelmente, o narrador foge ao final do conto, ou, mais especificamente, pelo que a personagem se culpa e do que tem medo. Seria conveniente, pois, reler os dois parágrafos finais da narrativa, nos quais se evidencia o temor que o filho sente do pai e do "além" que ele representa, um além que é a morte em vida. Explorar os possíveis sentidos dessa "morte em vida", bem como, de modo mais geral, a relação que o ser humano trava com a morte, consiste aqui num aspecto de relevo, especialmente porque, numa das chaves de leitura do conto, a terceira margem do rio pode ser pensada como o desconhecido, que permeia e oprime a existência do homem em sua travessia pela vida rumo à morte. ${ }^{4}$ Contudo, admitindo-se que o conto permanentemente agencia variados "lugares de incerteza", construindo-se por meio de lacunas e sugestões frequentemente indiretas, cabe ao professor atentar para os limites e condições de possibilidade da leitura aqui encaminhada, a ser enriquecida e mesmo confrontada por abordagens concorrentes, surgidas naturalmente ao longo da discussão. 


\section{Proposta de atividades}

A fim de consolidar as reflexões produzidas na leitura crítica, o docente poderia propor aos alunos diversas atividades avaliativas. A ideia é que, por meio delas, o estudante possa retomar aspectos discutidos nas etapas anteriores, operando as seleções, reconfigurações e ampliações necessárias para a boa execução da proposta. Aqui, apenas sugerem-se três encaminhamentos dentre muitos possíveis, ora valorizando-se movimentos analítico-interpretativos ancorados em leituras comparativas, ora valorizando-se incursões propriamente criativas, que necessariamente dão notícia, também, de uma dada interpretação do conto roseano. Para todos eles, convém lembrar que o acompanhamento do professor deve se estender pelo processo como um todo, dividindo-o em etapas mediante as quais seja possível, em conjunto com os alunos, avaliar o andamento parcial da proposta e planejar, com base nesse diagnóstico, os passos subsequentes. Dito isto, algumas das atividades poderiam consistir nas seguintes:

1) Em grupos de até cinco integrantes, efetuar uma adaptação paródica ou estilizada do conto (peça teatral, vídeo, animação, história em quadrinhos). Importa avaliar o processo como um todo, desde a ideia original, passando pela confecção de storyboard ou de roteiros, quando for o caso, até o produto final.

2) Em duplas ou trios, selecionar qualquer produção artística (literária, musical, cinematográfica) relacionada à temática do conto estudado. Novamente, interessa acompanhar o processo desde a seleção do objeto a ser comparado, passando pelos aspectos efetivamente a serem realçados na associação, até a entrega da versão final do trabalho, que deve ser apresentado à turma.

3) Elaborar uma análise comparativa, individualmente ou em dupla, entre o conto e a animação dirigida por Alê Abreu, O menino e o mundo (2014), com a finalidade de traçar semelhanças e diferenças entre as duas produções artísticas. $\mathrm{Na}$ animação $\mathrm{O}$ menino e o mundo, a ausência paterna é a grande desencadeadora do enredo: o menino, sentindo falta do pai, o qual sai do campo em busca de um trabalho na cidade, parte para conhecer o novo mundo para onde foi seu progenitor, encontrando miséria, pobreza, desigualdade, mas também esperança de um renascer. Aos olhos do menino, a vida é uma travessia da infância à velhice, é o desconhecido - a "terceira margem do rio" - ao qual o homem está condicionado. Além da temática da ausência paterna, a língua portuguesa aparece substituída por uma língua não convencional e inventada, donde se percebem, de imediato, duas frentes possíveis de exploração do conto e da animação, respeitando-se as suas respectivas especificidades. Para 
essa atividade, também seria solicitada a entrega da versão escrita do trabalho e a apresentação da análise produzida aos companheiros de classe, depois, naturalmente, de o professor acompanhar o processo de elaboração como um todo.

Ao final, depois das apresentações, seria promovido um último debate com a sala, no qual seria discutido o processo de elaboração dos trabalhos, suas produções e impressões de leitura, observando-se a manutenção de um clima favorável ao diálogo, sendo este essencial à formação de sujeitos leitores: "[...] um contexto onde reinam a confiança, o respeito e a escuta mútuos é propício ao encontro com os textos literários - e é mesmo determinante." (ROUXEL, 2013, p.30)

\section{Considerações finais}

Conclui-se que é essencial ao professor de literatura a reflexão e a fundamentação teórica de sua prática, tal qual o reconhecimento de seu papel enquanto mediador na dinâmica leitor e obra, como previsto nos documentos oficiais. Assim, efetuando possíveis acomodações como as sugeridas na proposta apresentada, o professor estimularia o aluno a se posicionar criticamente frente a diferentes discursos, desenvolvendo suas habilidades e competências leitoras.

Espera-se, dessa forma, que a abordagem apresentada do conto “A terceira margem do rio" seja uma alternativa, dentre muitas outras, de atender as diversas necessidades dos alunos em suas peculiaridades, bem como que contribua para o amadurecimento literário e mesmo afetivo da turma, tendo em vista que o contato, devidamente mediado, com um texto tão rico em possibilidades interpretativas, tende a evocar sentimentos com os quais as pessoas, em situação de ensino-aprendizagem ou não, convivem cotidianamente, bem como conhecimentos vários acerca do mundo em que vivem.

Em um contexto de sala de aula, permitir que os alunos façam intervenções, questionem, utilizem dos meios dos quais dispõem para a melhor compreensão textual (como as novas tecnologias, mas não apenas elas) e relacionem um conto produzido no século XX a dilemas contemporâneos permite, desde que tais movimentos se deem segundo uma organização e gradação pertinentes, que a literatura seja valorizada e cumpra o seu papel formador na educação, em contraste com o que se concebe, de modo redutor, como "pedagogia oficial": 
A literatura pode formar; mas não segundo a pedagogia oficial, que costuma vê-la ideologicamente como um veículo da tríade famosa, - o Verdadeiro, o Bom, o Belo, definidos conforme os interesses dos grupos dominantes, para reforço da sua concepção de vida. Longe de ser um apêndice da instrução moral e cívica, [...] ela age com o impacto indiscriminado da própria vida e educa como ela, - com altos e baixos, luzes e sombras. (CANDIDO, 1999, p.84).

\section{Notas}

1 Tese formulada por Gilles Thérien (1990) em sua obra Pour une sémiotique de la lecture.

2 “A leitura é o processo no qual o leitor realiza um trabalho ativo de compreensão e interpretação do texto, a partir de seus objetivos, de seu conhecimento sobre o assunto, sobre o autor, de tudo o que sabe sobre a linguagem etc. Não se trata de extrair informação, decodificando letra por letra, palavra por palavra. Trata-se de uma atividade que implica estratégias de seleção, antecipação, inferência e verificação, sem as quais não é possível proficiência.” (BRASIL, 1998, p.69).

3 As Orientações Curriculares para o Ensino Médio (OCEM) afirmam que “[...] nos programas pedagógicos são reforçadas as propostas de interdisciplinaridade, transdisciplinaridade, transversalidade. O intuito delas é promover a expansão da compreensão de mundo, pois pretendem ensinar os alunos a entender as relações entre as disciplinas pedagógicas - em vez de ensinar as matérias escolares de maneira isolada, ou seja, voltadas para si mesmas - e as disciplinas escolares, e delas com a sociedade e a vida dos alunos. O resultado esperado deve reverter para a compreensão da complexidade social em que vivem os cidadãos (no caso, alunos, professores, pais, familiares), sendo a questão da diversidade um dos componentes dessa complexidade." (BRASIL, 2006, p. 94)

4 “Sob a lei do insólito, o familiar torna-se estranho (o pai-fantasma, sombra do pai conhecido) [...]" (PACHECO, 2006, p. 153)

\section{Referências}

BRAGANÇA, Soraya Patrícia Rossi. O inferno em “A terceira margem do rio". In:

DUARTE, Lélia Parreira (Org.). Veredas de Rosa. Belo Horizonte: PUC-MG, 2000, p. 662665.

BRASIL. Parâmetros curriculares nacionais: Terceiro e quarto ciclo do ensino fundamental: língua portuguesa. Brasília: MEC/SEF, 1998.

. Orientações curriculares para o ensino médio. Brasília: MEC/Secretaria da Educação, 2006. 
CANDIDO, Antonio. A literatura e a formação do homem. Remate de Males. Revista do Departamento de Teoria Literária IEL/ UNICAMP, Número Especial Antonio Candido. Campinas, Anual, 1999, p. 81-90.

COSSON, Rildo. Círculos de leitura e letramento literário. São Paulo: Editora Contexto, 2014.

DALVI, Maria Amélia. Literatura na Escola: propostas didático-metodológicas. In: DALVI, Maria Amélia; REZENDE, Neide Luzia; JOUVER-FALEIROS, Rita. Leitura de literatura na escola. São Paulo: Parábola, 2013. p. 67-97.

DAL FARRA, Maria Lúcia. O narrador ensimesmado: o foco narrativo em Vergílio Ferreira. São Paulo, Ática, 1978.

JOUVE, Vicent. O que é leitura? In: - A leitura. São Paulo: Editora da Unesp, 2002. cap. 1, p. 17-33. Por que estudar literatura? São Paulo: Parábola, 2012.

LIMIA, Júlia. A terceira margem do rio. In: DUARTE, Lélia Parreira (Org.). Veredas de Rosa. Belo Horizonte: PUC-MG, 2000, p. 327-331.

NEVES, Carmen Moreira de Castro. Formação de professores da educação básica e pósgraduação: a interdisciplinaridade necessária. In: FERNANDES, Valdir; PHILLIPPI JÚNIOR, Arlindo. Práticas da interdisciplinaridade no ensino e pesquisa. 2015, p. 471-499.

OSAKABE, Haquira. Poesia e indiferença. PAIVA, Aparecida (Org.) et al. Leituras Literárias: discursos transitivos. Belo Horizonte: Ceale/ Autêntica, 2008, p. 37-54.

PACHECO, Ana Paula. Lugar do mito: narrativa e processo social nas Primeiras estórias de Guimarães Rosa. São Paulo: Nankin, 2006.

PENNAC, Daniel. Como um romance. (trad. Leny Werneck). Rio de Janeiro: Rocco, 1993. 
ROJO, Roxane; ALMEIDA, Eduardo de Moura (Org.). Multiletramentos na escola. São Paulo: Parábola editorial, 2012.

ROUXEL, Annie. Aspectos metodológicos do ensino da literatura. In: DALVI, Maria Amélia; REZENDE, Neide Luzia; JOUVER-FALEIROS, Rita. Leitura de literatura na escola. São Paulo: Parábola, 2013, p. 17-33

RÓNAI, Paulo. Os vastos espaços. In: ROSA, João Guimarães. Primeiras estórias. Rio de Janeiro: José Olympio, 1981, p. XX-XLVI.

ROSA, J. G. A terceira margem do rio. In: Primeiras estórias. Rio de Janeiro: José Olympio, 1981, p. 27-32.

recebido em 01 out. 2018 / aprovado em 19 nov. 2018

Para referenciar este texto:

NETO, J. S. V.; BERTÃO, L. S. P.; KIKUCHI, N. M. D. Entre margens: Guimarães Rosa na sala de aula. Dialogia, São Paulo, n. 30, p. 47-58, set. /dez. 2018. Disponível em: $<$ https://doi.org/10.5585/Dialogia.n30.10626> 